\title{
The influence of the degree of iron-ore enrichment on it's metallization parameters
}

\author{
A. M. Amdur ${ }^{1}$, A. E. Pelevin ${ }^{1}$, Barnasan Purevsuren ${ }^{2, *}$, \\ Lkhamsuren Munkhtuul ${ }^{1}$, A. L. Raznitsina ${ }^{1}$ \\ ${ }^{1}$ Ural State Mining University, Yekaterinburg City, Russia \\ ${ }^{2}$ Institute of Chemistry and Chemical Technology, Mongolian Academy of Sciences, \\ Ulaanbaatar - 51, Mongolia \\ *E-mail address: bpurevsuren.icct@gmail.com
}

\begin{abstract}
Have been developed a scheme of enrichment (benification) of magnetite iron-ore concentrates with total content of $\mathrm{Fe}_{\mathrm{t}}=31 \%$ in ore at magnetic separator and obtained a superconcentrate with $\mathrm{Fe}_{\mathrm{t}}$ $=69,50 \%$. Experimentally determined that the reduction reaction degree of $\mathrm{Fe}$ by coal increases linearly with increasing of the content of $\mathrm{Fe}$ in concentrate. Certainly it has positive influence of decreasing the content of more difficult for reduction and poor magnetic iron containing components in the processing of wet magnetic separation (WMS). Almost all iron are in the form of good to reduce magnetite in the superconcentrates and enrichment of concentrate accompanying with growth of specific surface.
\end{abstract}

Keywords: Fe; iron-ore; coal; magnetite ore; production of superconcentrate; enrichment of ore

\section{INTRODUCTION}

There is a world-wide growth of metalized raw materials for their well known advantages. For example technology of metallization by using of coal as a reductor is developing rapidly (SL/RN, Tisco et al. ) and it's quota increased more than $23 \%$ in the world production. As it is known usually uses rich concentrate of magnetite ore for production of metalized raw material. For this reason necessary to investigate how to be influenced the rate of reduction reaction of $\mathrm{Fe}$ against enrichment's degree of iron concentrate.

\section{EXPERIMENTAL}

Experimental testing enrichment of magnetite iron-ore-concentrate with total content of $\mathrm{Fe}_{\mathrm{t}}=31.0 \%$ in ore from the Sutar deposit, Russia have been carried out in a magnetic separator designed by us [2]. 


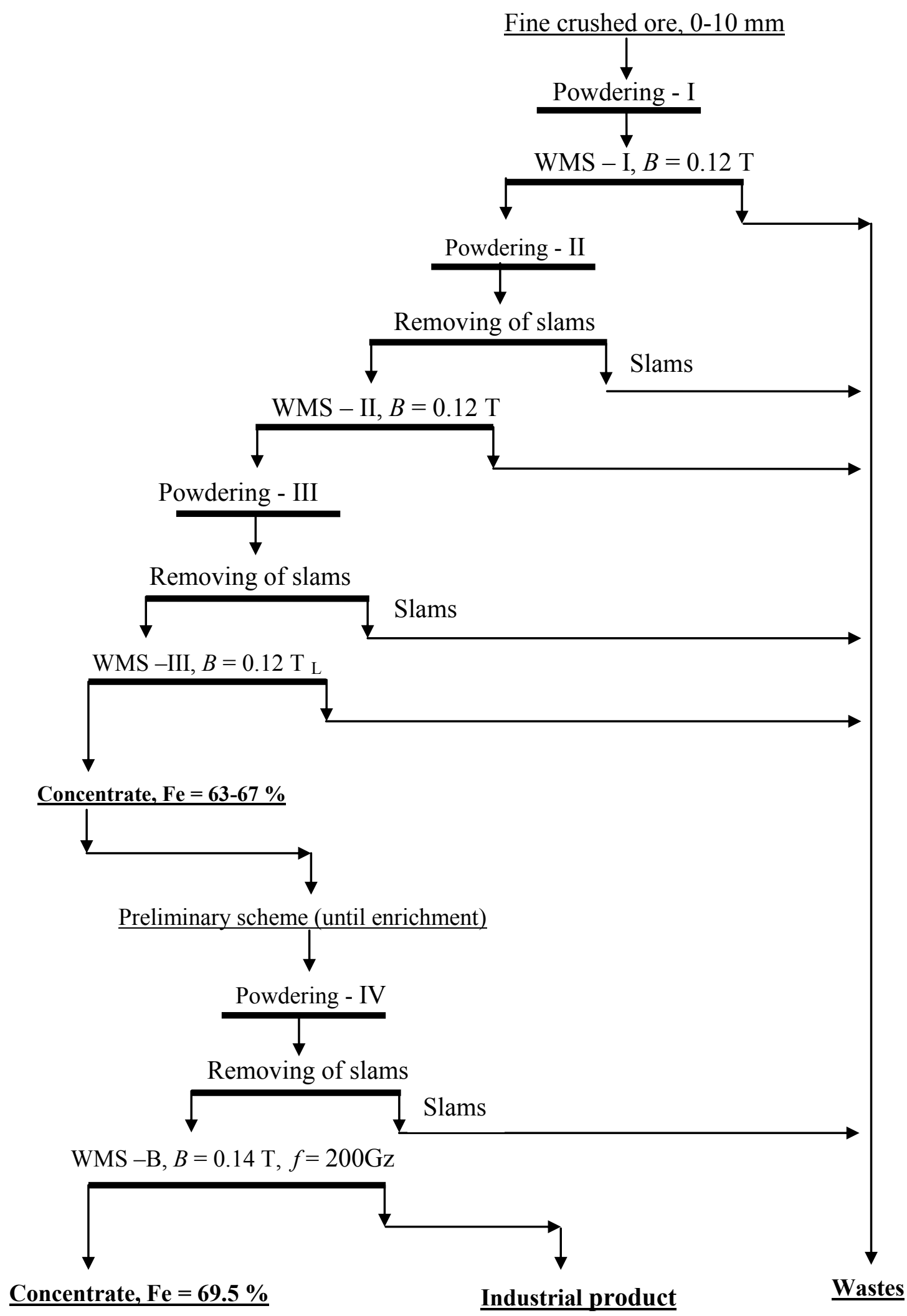

Figure 1. Scheme of enrichment of ore from Sutar deposit for production of superconcentrate (WMSWet Magnetic Separation). 
An iron concentrate with total content of $\mathrm{Fe}_{\mathrm{t}}=63-67 \%$ was obtained at a laboratory condition by 3 stage milling, magnetic separation of iron concentrate and isolation of tilt after each operation of changing the size of pieces.

The powdered products processed by desliming and wet magnetic separation (two testing, $\mathrm{B}=0,12 \mathrm{~T}$ ). The mass portion of $\mathrm{Fe}$ increases and the same of $\mathrm{SiO}_{2}$ decreases in the concentrate when increases it's thinness of grinding. The scheme of enrichment is shown in Figure 1.

Iron concentrate with mass portion of $\mathrm{Fe}=69,5 \%$ obtained by next enrichment of concentrate with mass portion of $\mathrm{Fe}=69,5 \%$. The next enrichment consists of grinding of concentrate, additional enrichment (until enrichment) and separation in a runner magnetic field (two testing, $\mathrm{B}=0,12 \mathrm{~T}, \mathrm{f}=200 \mathrm{Gz}$ ). For investigation of the dependence of $\mathrm{Fe}$ content on the degree of it's metallization have been investigated the losses value versus temperature and content of $\mathrm{Fe}_{\mathrm{t}}$ in concentrate.

Testing samples were prepared as a mixed briquette with size $21 * 6 \mathrm{~mm}$ by mixing and pressing of following components: concentrate with piece $-0,071 \mathrm{~mm}$, coal $-0,10 \mathrm{~mm}$, and bentonite $-0,02 \mathrm{~mm}$ ( $5 \%$ to the mass of briquette) as a binding material. As a reduction agent was used lignite coal of Shariingol deposit from Mongolia with elemental carbon $\mathrm{C}^{\text {daf }}-77,7$ $\%$, content of ash $-7,67 \%$ and volatile matters $\mathrm{V}^{\mathrm{daf}}-36,88 \%$.

Previously have been determined that this coal is a efficient reduction agent [1]. The quantity of necessary carbon in briquette was fixed by stechiometrical calculation for fully reduction of iron oxide $-\mathrm{Fe}_{2} \mathrm{O}_{3}$. The specific gravity of samples was $2300 \mathrm{~kg} / \mathrm{m}^{3}$ and dried them in oven at temperature $120^{\circ} \mathrm{C}$ for 2 hours. The burning of reduction reaction of samples was carried out in a furnace with regulator of temperature for 60 minute.

\section{RESULTS AND DISCUSSION}

The worked out by us technology permits to obtain a concentrates with high content of iron and determined characteristics of concentrates after enrichment are given in Table 1 . The iron concentrates are characterizing as high magnetic magnetite and obtained by magnetic method in a condition of high magnetic field. Increasing the mass portion of iron-Fe in initial concentrate leads to increasing also mass portion of magnetite in the product and reaches to $100 \%$. Except magnetite also content mixed mineral of magnetite with quartz, gematite and grunerite in the investigated concentrates (Figure 2).

Table 1. The characteristics of concentrates after enrichment.

\begin{tabular}{|c|c|c|c|}
\hline \multirow{2}{*}{$№$} & \multicolumn{2}{|c|}{ Mass portion, \% } & $\begin{array}{c}\text { The portion of } \\
\text { fraction }-0,045 \mathrm{~mm}, \%\end{array}$ \\
\cline { 2 - 4 } & $\mathrm{Fe}$ & $\mathrm{SiO}_{2}$ & 87,0 \\
\hline 1 & 63,07 & 8,18 & 91,3 \\
\hline 3 & 65,00 & 7,48 & 97,1 \\
\hline 4 & 67,00 & 5,34 & 99,8 \\
\hline
\end{tabular}




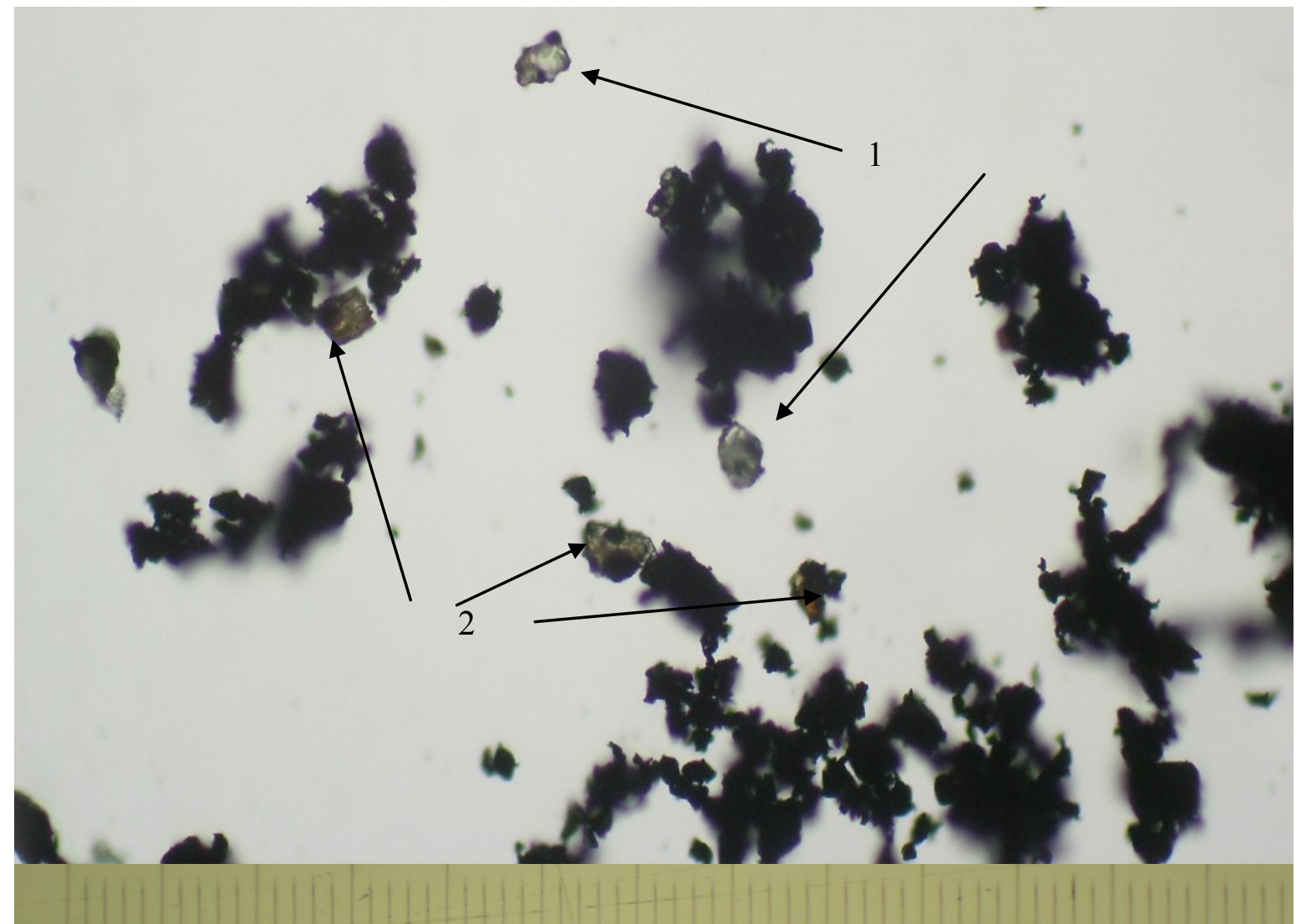

Figure 2. Corn-particles in the Sutar concentrate with $67 \%$ mass portion of iron (Fe).

1. Corn-particles of quartz with magnetite; 2 . Corn-particles of granitite with, magnetite; (one scale is equal $0.01 \mathrm{~mm}$ ).

In spite of lower magnetite properties of these minerals they can content as an small amounts of impurities in the magnetite concentrates. The mass portion of iron $-\mathrm{Fe}$ is about $71,7-72,4 \%$ in the magnetite and it is very close to the stechiometrical value. Gematite contains about $98 \%$ of $\mathrm{Fe}_{2} \mathrm{O}_{3}$.

Table 1. The characteristics of concentrates after enrichment.

\begin{tabular}{|c|c|c|c|}
\hline \multirow{2}{*}{ № } & \multicolumn{2}{|c|}{ Mass portion, \% } & $\begin{array}{c}\text { The portion of } \\
\text { fraction }-0,045 \mathrm{~mm}, \%\end{array}$ \\
\cline { 2 - 4 } & $\mathrm{Fe}$ & $\mathrm{SiO}_{2}$ & 87,0 \\
\hline 1 & 63,07 & 8,18 & 91,3 \\
\hline 2 & 65,00 & 7,48 & 97,1 \\
\hline 3 & 67,00 & 5,34 & 99,8 \\
\hline
\end{tabular}


The granitite belongs to the group of grunerite amphibols with higher content of mass portion of iron - $\mathrm{Fe}(22,67 \%)$ and content of $\mathrm{SiO}_{2} 54,58 \%$ in the investigated concentrates.

As a result have been obtained products with degree of metallization more than $92 \%$ and content of $\mathrm{FeO} 7,84-11,31 \%$ after reduction process by coal. The quantity of $\mathrm{Fe}_{\mathrm{t}}$ after metallization of concentrate with initial content of $\mathrm{Fe}_{\mathrm{t}}=69,5 \%$ is $92 \%$ at $1100{ }^{\circ} \mathrm{C}$ without using of bentonite as a binding material and this result is very close to the same results of Lebedinsk superconcentrates after metallization of raw materials.

Have been done regression analysis of initial experimental dates in a coordinate of mass loss versus content of iron in the concentrates at different temperature and have been chosen a linear polynomial type of relationship for the experimental results. Have been determined the residual dispersion error of prediction, averaged quadratic error of prediction and maximum error of prediction. On the basis of these date and by using criteria of Student have been calculated the error of reproduction and confidential interval.

After these calculations have been shown that maximum error (mistakes) of average mass changing during reduction reactions at temperature $900-1100{ }^{\circ} \mathrm{C}$ is $3,8 \%$ which is at confidential intervals.

According to this result the degree of reduction reaction increases with increasing of iron content $\mathrm{Fe}_{t}$ in the initial concentrate by linear relationship and increases also with increasing of temperature. This result also can be confirmed by the dates of chemical analysis results shown in Figure 3-4 obtained by approximation according to the above mentioned linear equation:

$$
\begin{aligned}
& {\left[\mathrm{Fe}_{\mathrm{m}}\right]=2,3484\left[\mathrm{Fe}_{\mathrm{t}}\right]-74,199 ; \mathrm{R}^{2}=0.98 \text { at } 1000{ }^{\circ} \mathrm{C} \text {; }} \\
& {\left[\mathrm{Fe}_{\mathrm{m}}\right]=1,3587\left[\mathrm{Fe}_{\mathrm{t}}\right]-3,2889 ; \mathrm{R}^{2}=0.90 \text { at } 1100{ }^{\circ} \mathrm{C} \text {. }}
\end{aligned}
$$

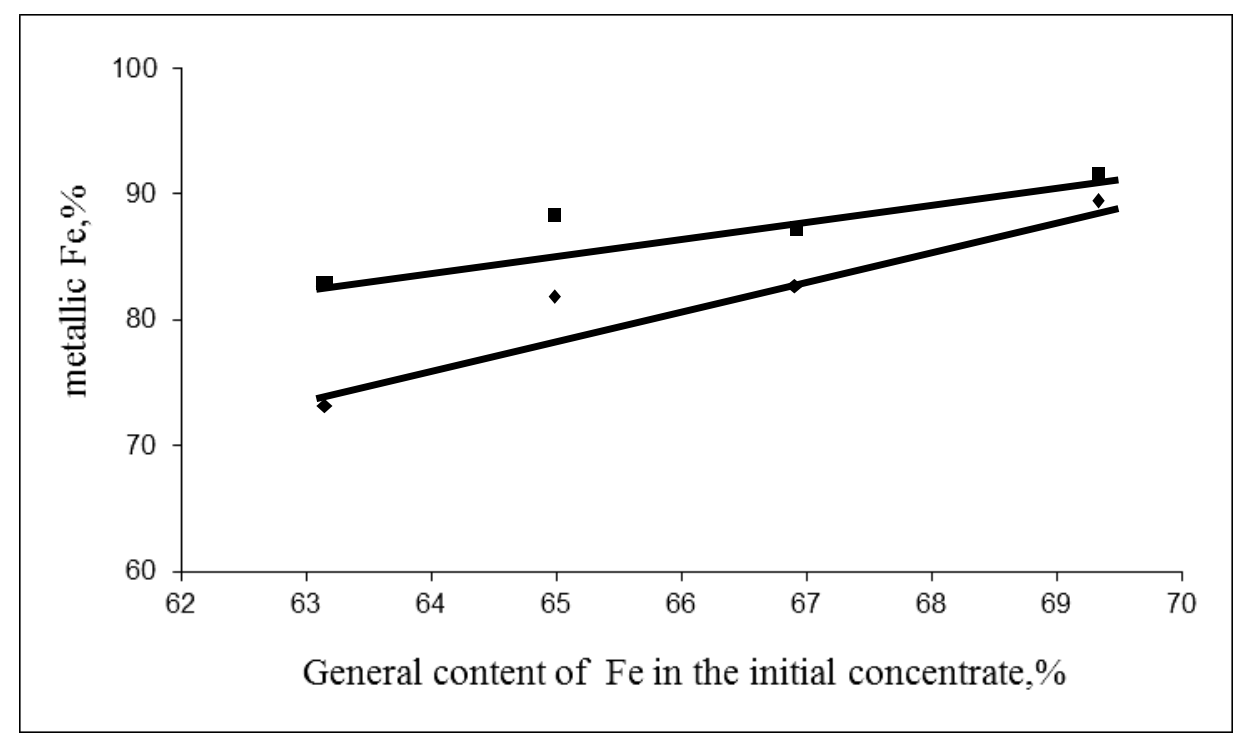

Figure 3. Reduction of iron-ore concentrate from Sutar deposit by brown coal: - at temperature $1000{ }^{\circ} \mathrm{C} ; \boldsymbol{-}-$ at temperature $1100^{\circ} \mathrm{C}$; time of keeping at temperatures 60 minute. 


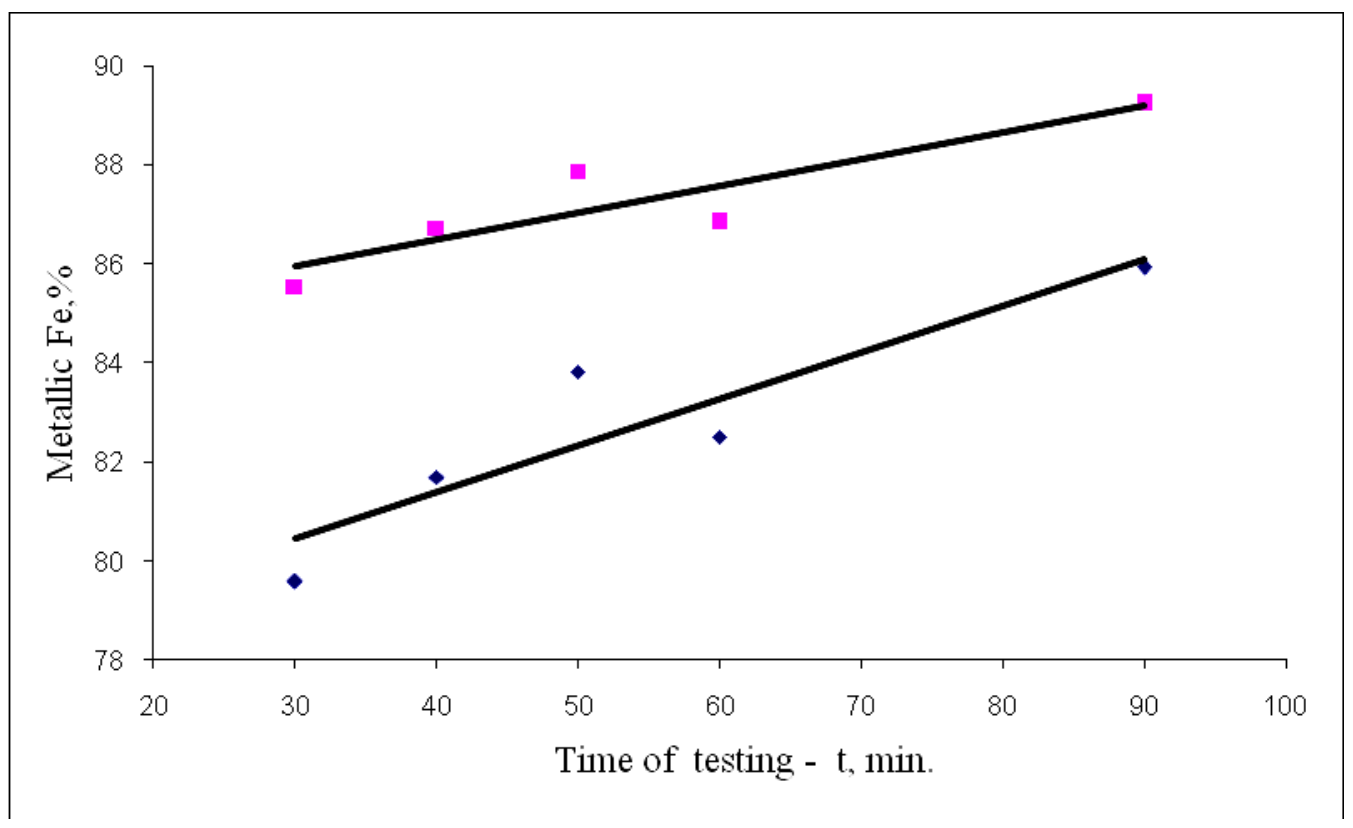

Figure 4. Reduction of iron-ore concentrate from Tamir deposit by brown coal: - Initial content of iron $-63,43 \%$; - Initial content of iron $-66,65 \%$;

The exposed dependence related with decreasing content of hard to reduce and poor magnetic iron-containing components during the process of wet magnetic separation. Therefore practically all irons $\left(\mathrm{Fe}_{\mathrm{t}}=69,50 \%\right)$ in the superconcentrate are in the form of well to reduce magnetite and also there is a growth of their specific surface during the enrichment of the concentrate (Table 1).

\section{CONCLUSIONS}

Worked out a technological scheme of enrichment in magnetic separator to produce a superconcentrates for magnetite type of iron-ore concentrates with total iron content $\mathrm{Fe}_{\mathrm{t}}=31$ $\%$ in ore from the Sutar deposit, Russia.

Experimentally determined that the degree of reduction reaction of iron by coal increases by linear relationship when increase the content of iron in concentrates and this is connected with decreasing content of hard to reduce and poor magnetic iron-containing components during the process of wet magnetic separation.

Practically all irons $\left(\mathrm{Fe}_{\mathrm{t}}=69,50 \%\right)$ in the superconcentrate are in the form of well to reduce magnetite and also there is a growth of their specific surface during the enrichment of the concentrate.

\section{Acknowledgment}

This work is performed by the financial support of Russian Fund of Fundamental Investigation and Science-Technology Fund of Mongolia. 


\section{References}

[1] Pleven A. E., Separation of iron concentrate by stage // Enrichment of ore 3 (2007) $10-15$.

[2] Amdur A. M., Munkhtuul L., Blagin D. B., Raznizina A. L. The role of products of thermal destruction of coal in the process of metallization for iron-or materials, Proceedings of the Mongolian Academy of Sciences 2 (2010) 41-48. 